Research Article

\title{
Crack Detection of Reinforced Concrete Member Using Rayleigh-Based Distributed Optic Fiber Strain Sensing System
}

\author{
Tingjin Liu $\mathbb{D}^{1,2}$ Honghao Huang $\mathbb{D}^{2},{ }^{2}$ and Yubing Yang $\mathbb{D}^{3}$ \\ ${ }^{1}$ South China Institute of Geotechnical Engineering, State Key Laboratory of Subtropical Building Science, \\ South China University of Technology (SCUT), Guangzhou 510640, China \\ ${ }^{2}$ School of Civil Engineering and Transportation, South China University of Technology (SCUT), Guangzhou 510640, China \\ ${ }^{3}$ College of Water Conservancy and Civil Engineering, South China Agricultural University (SCAU), Guangzhou 510642, China
}

Correspondence should be addressed to Yubing Yang; yubingyang@msn.com

Received 3 November 2019; Revised 12 June 2020; Accepted 7 July 2020; Published 25 July 2020

Academic Editor: Claudio Mazzotti

Copyright (C) 2020 Tingjin Liu et al. This is an open access article distributed under the Creative Commons Attribution License, which permits unrestricted use, distribution, and reproduction in any medium, provided the original work is properly cited.

\begin{abstract}
Early detection of crack is critical for the maintenance of reinforced concrete (RC) structures. In this study, a distributed optical fiber (DOF) sensing system with Rayleigh Optical Frequency Domain Reflectometry (OFDR) technique was deployed to a member of RC structure in a full-scale laboratory experiment, which was subjected to a monotonic lateral load. With the aid of a high space resolution (up to $1 \mathrm{~mm}$ ) and measurement accuracy ( \pm 1 micro strain) interrogator (OSI-S by Semicon), continuous strain measurements inside of the RC member are elaborately implemented. The result of crack detection by the analysis of the measured tensile strain profiles is in excellent agreement with the visually observable cracks mapped during the test. This confirms the ability of the optical fiber inside of RC members to capture cracks on concrete surface. Moreover, the recognition of crack orientation and depth is accomplished by comparing strain measurements of optical fibers installed at multiple locations.
\end{abstract}

\section{Introduction}

Because of inherent weakness in tension, cracks can be observed in reinforced structures even in service loading. Cracks are one of the earliest indications of concrete structure degradation, which reduce local stiffness and cause material discontinuities and furthermore shorten the integrity and service life of structures. Therefore, the early detection of crack damage, initiation, localization, and characterization (crack width, length, and depth) are crucial parameters in the safety, maintenance, and durability of concrete structures.

Conventional monitoring methods that were employed to perform crack detection had serious limitations. The most common was to perform visual inspections and/or to use discrete sensors that generally were not able to locate existing cracks. The manual approach of visual inspection completely depends on the specialist's knowledge and experience, making it lack objectivity in quantitative analysis [1]. For the image-based crack monitoring systems, in most cases, it is essential to implement sophisticated methodologies to ensure the effectiveness of acquired images [2]. The use of discrete sensors was conditioned, since they are not able to predict where the crack could appear. The major limitation lies in the availability of locating cracks and quantifying cracking patterns in a timely manner.

Recent case histories have demonstrated the feasibility of distributed optical fiber (DOF) sensing system with Rayleigh Optical Frequency Domain Reflectometry (OFDR) technique in the crack detection of concrete structures [3-12]. The DOF sensing system employs optical fibers as sensing elements (i.e., sensor with a thousand of measuring points) to continuously measure the strain along the entire fiber length. By applying loads, the fibers are subjected to extension and contraction. A lot of imperfections are artificially made in the cylindrical geometry of fibers during the manufacturing process. The deformation of fibers leads the distances between these imperfections to change, which subsequently alters the frequency of the backscattered light. The characteristics of the backscattered light are measured before and after applying 
loads, which are analyzed and then converted to strain data. Three different types of backscattering processes may occur in a DOF sensor: Raman, Brillouin, and Rayleigh backscattering [9]. While the Raman scattering is characterized by the high dependence on temperature, it can also be used to extract physical and chemical information of a material such as food quality or explosive materials. Brillouin backscattering with an optical time domain (OTD) analysis, thanks to its extended measurement range capability (up to several kilometers), is the most studied and used DOFS system in civil and geotechnical engineering. The third scattering phenomenon is Rayleigh scattering with an optical frequency domain (OFD) analysis. Despite its 50 or $100 \mathrm{~m}$ sensing range limit, it can provide a high spatial resolution (up to $1 \mathrm{~mm}$ ), which is ideal for strain and damage monitoring in concrete structures.

In most cases, the optical fiber was bonded to the concrete surface to locate the crack [2-5] and then to assess crack width [2]. However, the other key characteristics of cracks, such as length and depth, are still unknown in this strategy. Fibers were also attached to reinforcement bars that will later be embedded in concrete to capture strains along the length of rebar in some experiments $[6,7,13-15]$, and it is demonstrated that the reinforcement strains recorded by optical fiber correlate perfectly with the position and opening of the cracks all over the concrete surface [6].

In this context, a distributed optical fiber-based concrete crack monitoring scheme was proposed, especially for the cases where concrete was confined in a container without a visible surface (see Figure 1), while its cracking was a critical issue with great concern. The checking of its effectiveness was carried out in a heavily reinforced concrete (RC) structure subjected to a concentrated load, a wall-beam-strut joint experiment at full scale. At first, optical fibers with a thin polyurethane elastomer coat were directly bonded on small-diameter steel bars and then were embedded in concrete structure. In order to fully capture the crack paths in the overall RC structure, the steel bars were installed at multiple locations to form a smart sensitive grid within the structure. Secondly, strains along the length of steel bar were recorded at different load levels. The identification of crack initiation, location, number, and crack characterization were expected to use the monitoring outcome provided by the optical fibers. Finally, the experimental crack mapping observed during the test will be compared.

\section{Experimental Program}

2.1. Test Setup and Loading Protocol. The DOF-based crack monitoring system was instrumented on a strut, which is a part of the wall-beam-strut joint made of reinforced concrete (see Figure 2). It was a full-scale experiment conducted in the Structural Laboratory of South China University of Technology (SCUT). The test setup consisted of reaction frames made from hollow steel sections, including lateral bracing in the direction of loading as shown in Figure 2. The RC joint structure was tested vertically because of the actuator orientation. The model was supported by part of the reaction

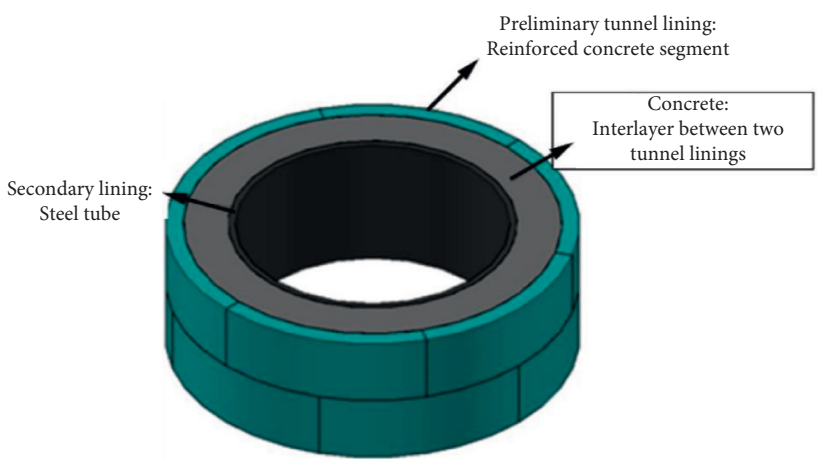

Figure 1: Concrete confined by two tunnel linings.

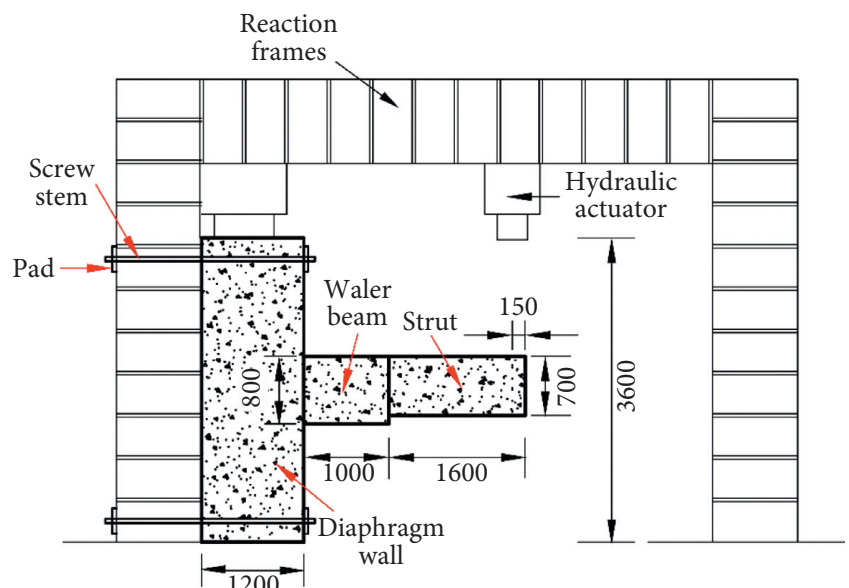

Figure 2: Test setup details (unit: mm).

frames using screw stems and pads at the top and bottom of diaphragm wall.

The actuator has a capacity of $3000 \mathrm{kN}$ and applies the load to the strut at a distance of $0.15 \mathrm{~m}$ from the end of strut. The strut was subjected to a monotonic lateral load starting from $120 \mathrm{kN}$ until the failure at about $2600 \mathrm{kN}$; the detailed setup of loading steps is summarized in Table 1.

2.2. Test RC Member and Fiber Sensors. The dimension of wall-beam-strut joint and the configuration of reinforcing bars, stirrups, and optical fibers in the strut are presented in Figures 2 and 3 . The cross section of the strut was $700 \mathrm{~mm}$ in depth and $1000 \mathrm{~mm}$ in width. The longitudinal reinforcements used in the RC member (i.e., the strut) were of grade HRB400 (i.e., $f_{y}=400 \mathrm{MPa}$ ), D32 (i.e., deformed bars which are $32 \mathrm{~mm}$ in diameter) bars. The stirrups and the steel bars to attach optical fibers on were of grade HRB335, D12 (i.e., deformed bars which are $12 \mathrm{~mm}$ in diameter) bars.

The optical fiber sensor used in this study is a polyurethane elastomer-coated fiber with a diameter of $0.9 \mathrm{~mm}$, without any special protective coating in the sensing cable. The steel bars adopted to host the fiber have a length of $2 \mathrm{~m}$. However, when the fiber was glued to a groove of the steel bar, a transition zone and unglued section have to be left at both ends of the steel bar, resulting in a $1.6 \mathrm{~m}$ in length tightly glued section of optical fiber in each steel bar. The 
TABLE 1: Loading steps in the experiment.

\begin{tabular}{lc}
\hline Step & Load $(\mathrm{kN})$ \\
\hline 1 & 120 \\
2 & 200 \\
3 & 240 \\
4 & 300 \\
5 & 350 \\
6 & 400 \\
7 & 500 \\
8 & 600 \\
9 & 700 \\
10 & 800 \\
11 & 900 \\
12 & 1000 \\
13 & 1200 \\
14 & 1400 \\
15 & 1600 \\
16 & 1800 \\
17 & 2000 \\
18 & 2200 \\
19 & 2400 \\
20 & 2600 \\
\hline
\end{tabular}

length of tightly glued zone is defined as "effective measuring length." Outside the transition zone, the fibers were put into small rubber tubes (blue) to protect them during concrete casting.

Figure 4 shows the detailed layout of fiber sensors. A total number of 6 measuring lines, at top side and lateral side of the strut, were performed to form a sensitive grid and to provide the probability of capturing the strain measurement at different locations.

In the next stage, splicing was conducted to connect 3 optical fibers on each side together, which is essential for assembling to the data acquisition system. The ends of fibers were spliced using an arc fusion splicer (KL-300t by Nanjing Jilong, China), which led to a total fiber length of $23 \mathrm{~m}$ on the top side and $30 \mathrm{~m}$ on the lateral side.

\subsection{Rayleigh-Based Distributed Optic Fiber Strain} Measurement. The strain was measured using an optical distributed sensor interrogator (OSI-S by Semicon) along the length of fibers, as shown in Figure 5.

The system allows for strain measurement with a resolution of $1 \mathrm{~mm}$ along the fiber length, a sample acquisition rate up to $4 \mathrm{~Hz}$ in the case of a $1 \mathrm{~cm}$ spatial resolution, and $50 \mathrm{~cm}$ measuring length. A sensing accuracy of $\pm 0.1^{\circ} \mathrm{C}$ and \pm 1 microstrain can be achieved when a spatial resolution of $1 \mathrm{~cm}$ with a measuring length no more than $50 \mathrm{~m}$ was used. For the current study, strain measurements were conducted every $2 \mathrm{~cm}$ along the fibers. Note that while the cost of the individual fiber is fairly low, the cost of the measurement system can be quite high.

\section{Results and Discussion}

3.1. Failure of the RC Structure. Figure 6 shows the forcedisplacement relationship and damage status in the strut and waler beam at the last loading step. A drift ratio of the strut (i.e., lateral displacement divided by specimen length) was defined in the analysis. The first signs of flexural cracking (C1) were captured at a $0.1 \% \mathrm{drift}$, followed by the emergence of numerous small cracks (C2 C6) up to $0.5 \%$ drift, where a significant increase in maximum crack size, up to approximately $0.4 \mathrm{~mm}$ (measured using a crack width visualizer), was observed.

The structure showed approximately linear elastic behavior up to $0.5 \%$ drift $(1007.1 \mathrm{kN})$, followed by several phases with a gradual stiffness degradation (highlighted by blue, red, and magenta solid line, respectively), reaching a maximum lateral load of $2628 \mathrm{kN}$ at $4.8 \%$ drift. At a drift of $1.5 \%$, the 8 th crack in the beam was captured, where another significant increase in maximum crack size, up to approximately $1.2 \mathrm{~mm}$, was inspected as well. This drift level is very distinct because it corresponds to yield of top layer reinforcing bars (10D32, measured by strain gauges) on the tension side and a sharp increase in crack width. The test was terminated at a $5.4 \%$ drift due to the load drop with an increase of deformation. The concrete on the compression side was crushed as well.

3.2. Strain Profile in Steel Bars and Crack Distribution on the Top Side. The crack distribution in the concrete surface over the length of strut and beam at $0.15 \%$ drift level is given in Figure $7(\mathrm{a})$. The first crack (C1) was found at a very small drift of $0.1 \%$ and located approximately in the intersection between the waler beam and strut, $0.3 \mathrm{~m}$ from the starting point of fiber sensor as well, while the second crack (C2) was observed at $0.15 \%$ drift level with a $0.45 \mathrm{~m}$ distance from $\mathrm{C} 1$.

The measured strains from the embedded fibers $A, B$, and $\mathrm{C}$, installed in the vicinity of the top longitudinal reinforcement bars, are provided in Figures $7(\mathrm{~b}) \sim 7(\mathrm{~d})$. When the loading level is low (i.e., about $120 \mathrm{kN}$ ), the strain distribution is reasonably smooth, indicating that there is little or no significant cracking; however, with the loading increase, local spikes appeared in all the strain profiles, in accordance with the location where cracks $\mathrm{C} 1$ and $\mathrm{C} 2$ were observed. In this case, it might be concluded that the local spikes in the tensile strain profile of embedded fiber denote the location of cracks, which is in excellent agreement with experimental crack mapping observed during the test. The measuring system detected early cracking (C1) at a lower loading level of around $240 \mathrm{kN}$, while it became visible at a $300 \mathrm{kN}$ loading level corresponding to a $0.1 \%$ drift. It is demonstrated that the strain profiles obtained from the fiber attached to steel bars excellently located the cracks on concrete surface in this study. Previous studies $[2,12]$ reported that this success has been achieved as well by strain profiles measured on fiber glued to concrete surface.

Figure 8(a) presents the initiation and location of new cracks (C3 C6) by the visual inspection. Cracks C3 C5 were observed on strut at a $0.3 \%$ drift level, while C6 appeared later on the waler beam at a $0.45 \%$ drift level. These cracks can be identified easily from the strain profiles in Figures 8 (b) 8(d), except crack C6, ascribing to its location at the edge of sensing fibers. Strain profiles in fibers A, B, and $\mathrm{C}$ at $0.4 \%$ drift, which corresponds to a $700 \mathrm{kN}$ loading level, 


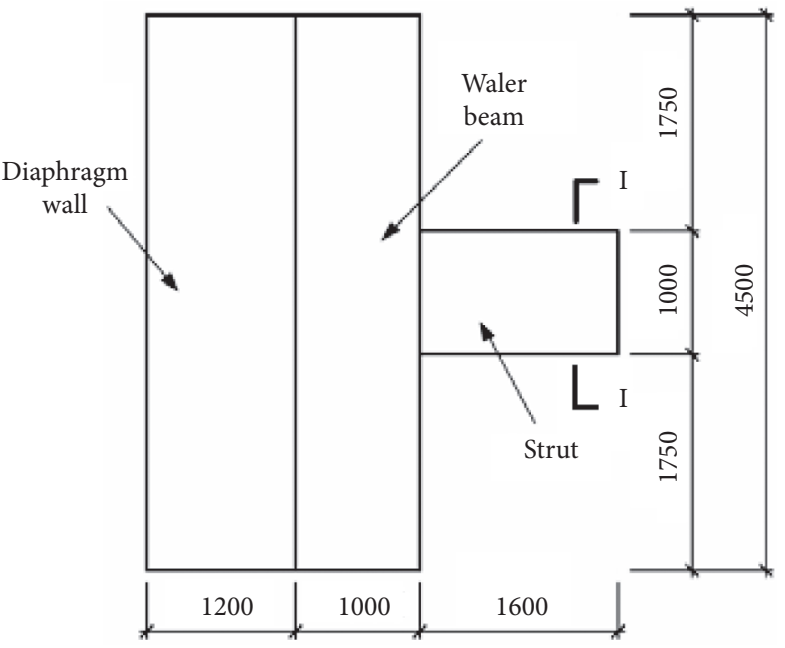

(a)

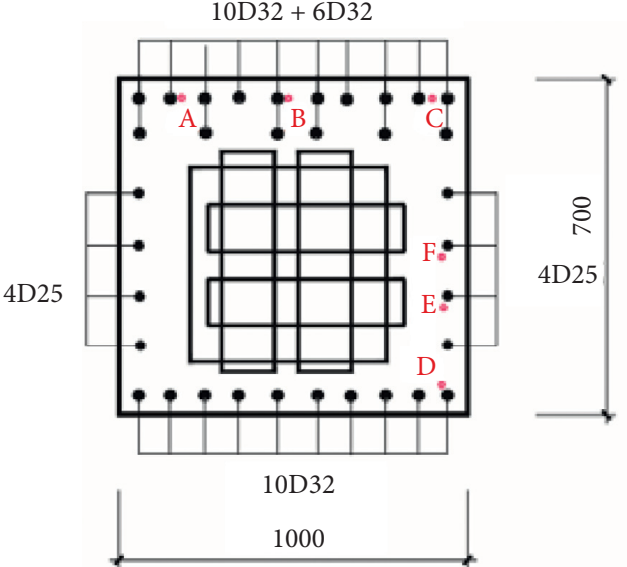

Sec I-I

(b)

Figure 3: Top view of the test structure and optic fiber arrangement (unit: $\mathrm{mm}$ ).

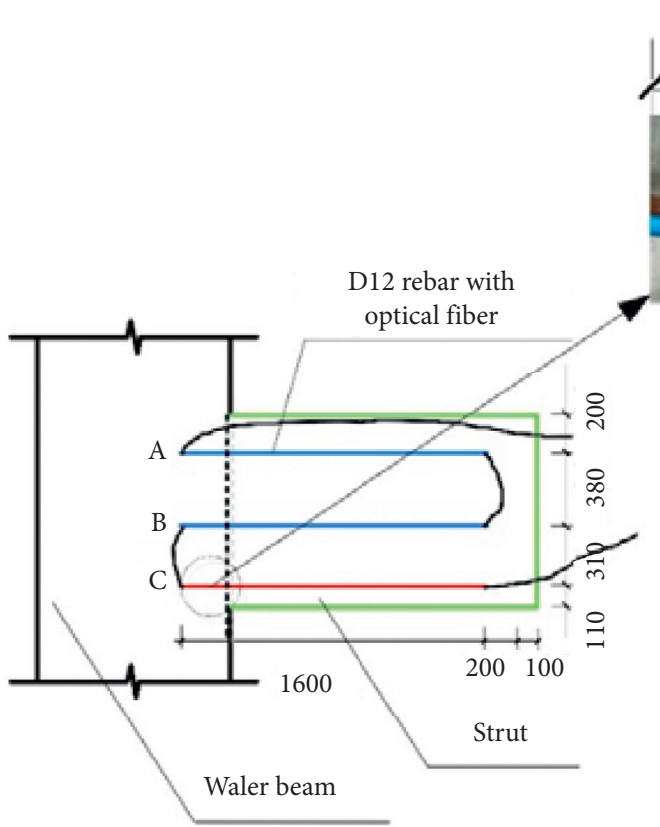

(a)
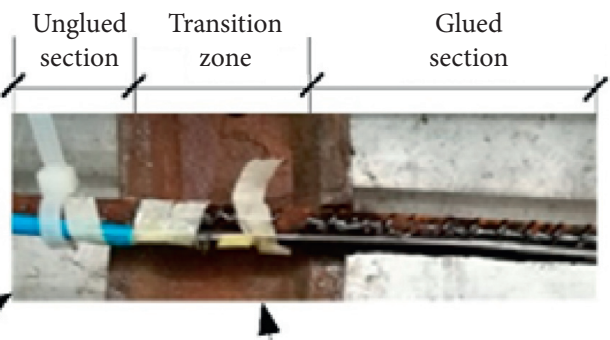

D12 rebar with optical fiber

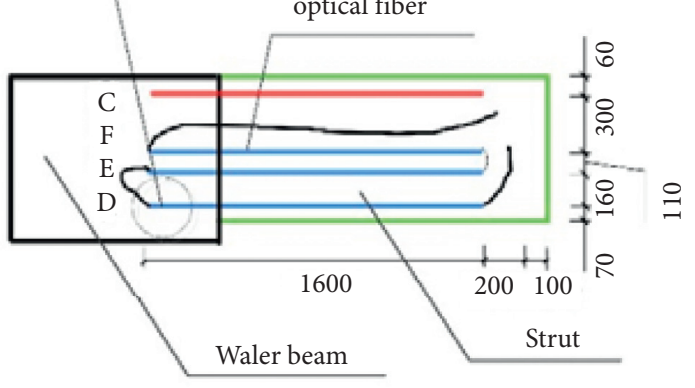

(b)

Figure 4: Layout of fibers inside the strut: (a) top view and (b) side view (unit: $\mathrm{mm}$ ).

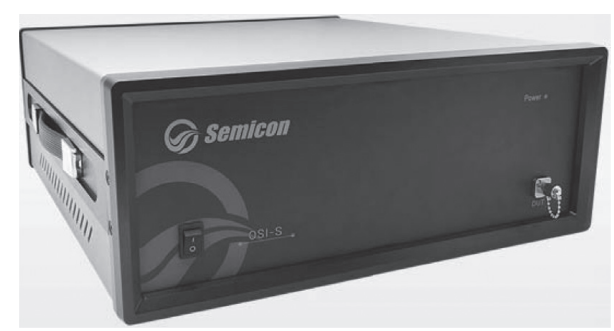

FIGURE 5: The Rayleigh OFDR-based interrogator (OSI-S by Semicon). are plotted as blue solid lines in the figures and, worth noting, a maximum crack width of $0.2 \mathrm{~mm}$ was measured, which is a significant crack size according to China's concrete structure design code [16].

Figure 9(a) shows the emergence of new cracks C7 and $\mathrm{C} 8$, located at the two ends of structure with distances of $-0.5 \mathrm{~m}$ and $1.2 \mathrm{~m}$ from crack $\mathrm{C} 1$, respectively. Crack C7 was still in the effective measuring length (i.e., $1.6 \mathrm{~m}$ long tightly glued zone) range of the fiber, while crack C8 was outside of this range, leading to an undetectable crack by fiber sensors.

Strain profiles measured along the length of steel bar A were given in Figure 9(b), which indicates a considerable 


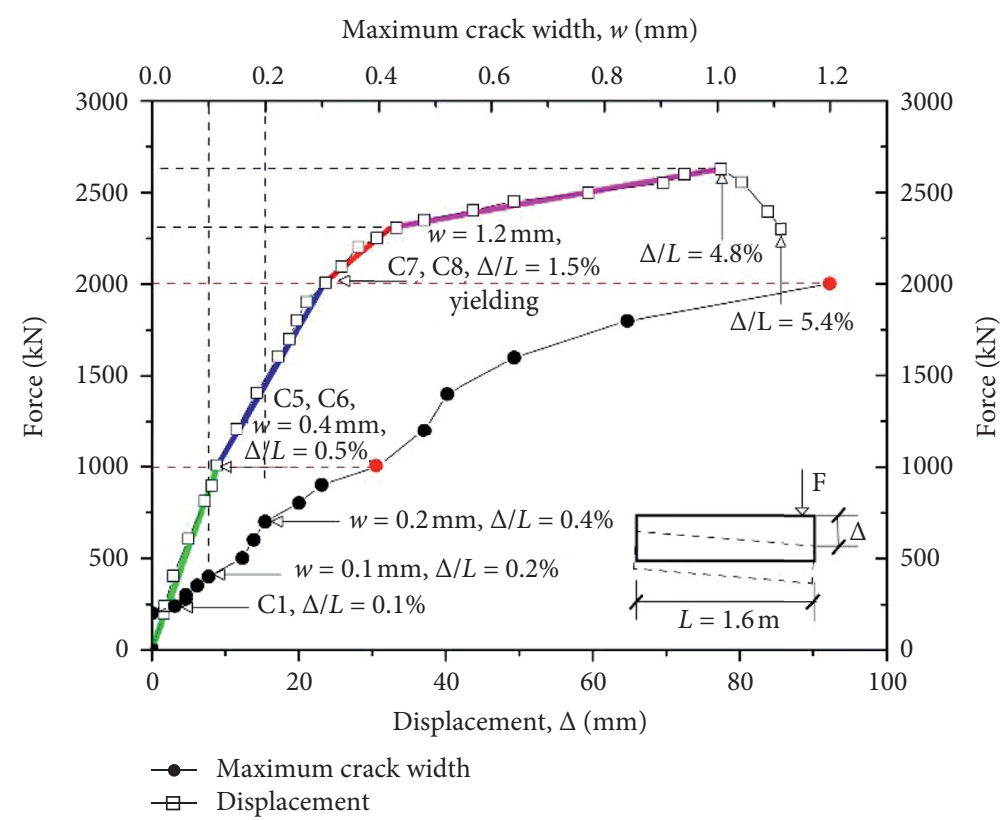

(a)

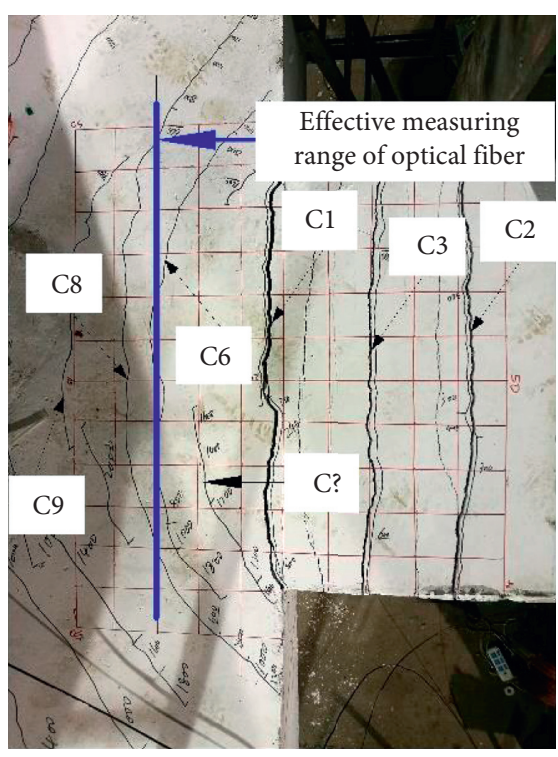

(b)

FIGURE 6: Force-displacement/maximum crack width and damage status at $\Delta / L=5.4 \%$ (top view).

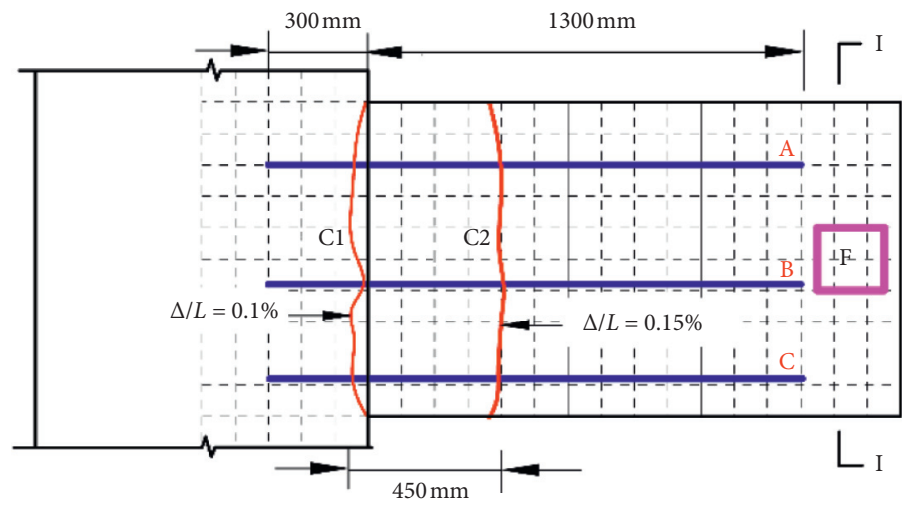

(a)

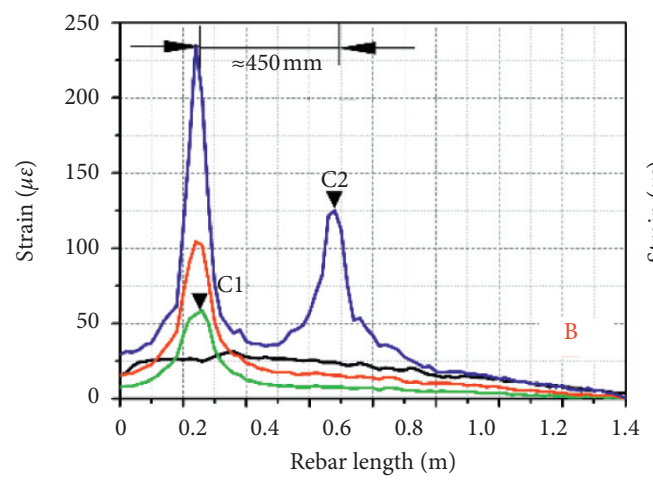

(c)

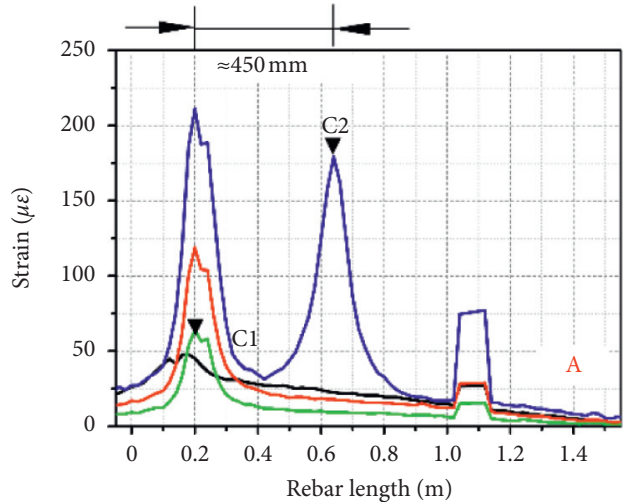

(b)
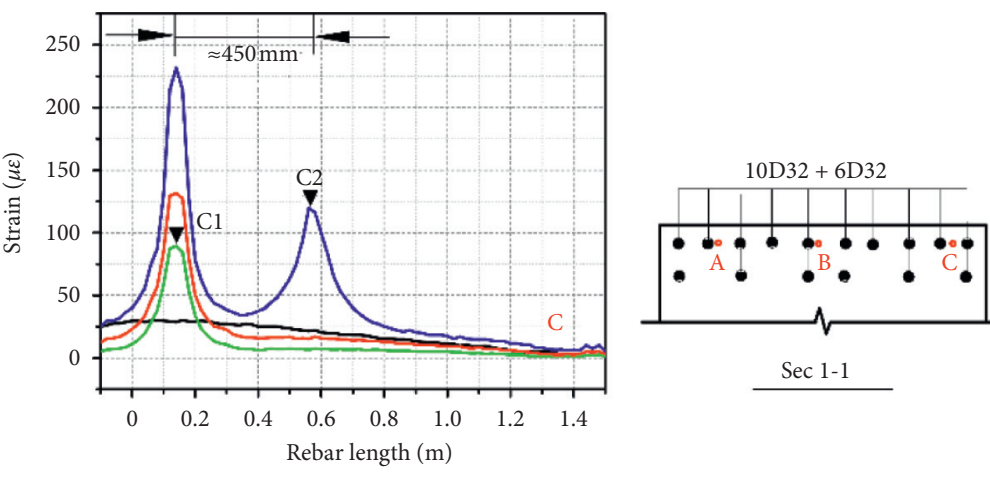

(d)

$\begin{aligned} &-120 \mathrm{kN} \\ &-200 \mathrm{kN}-240 \mathrm{kN}(\Delta / L=0.10 \%) \\ &-300 \mathrm{kN}(\Delta / L=0.15 \%)\end{aligned}$

Figure 7: Damage status at $0.15 \%$ drift (a) and strain profile measured in top fibers A, B, and C at drift levels below 0.15\% ((b), (c), and (d)). 


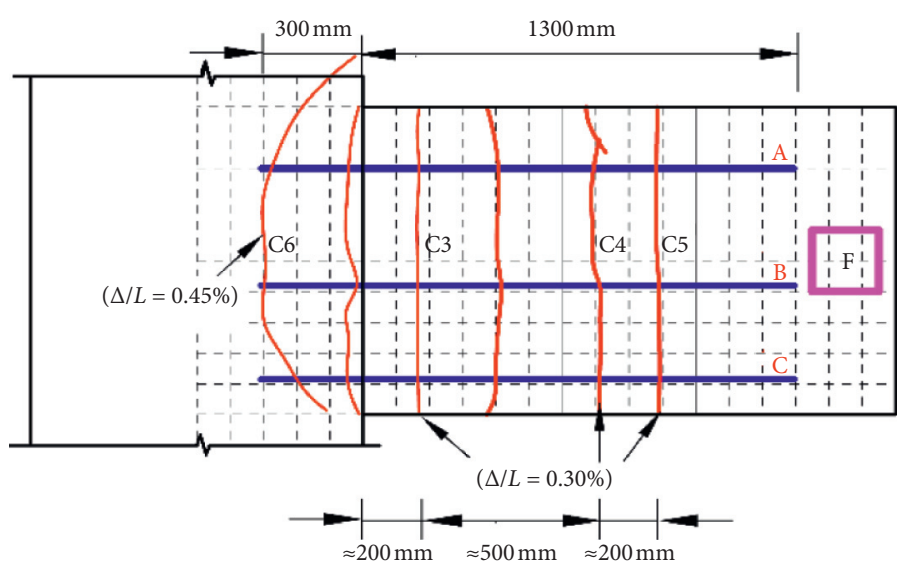

(a)

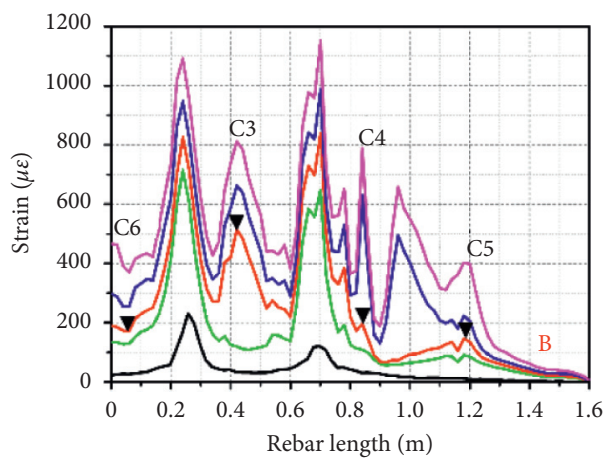

(c)

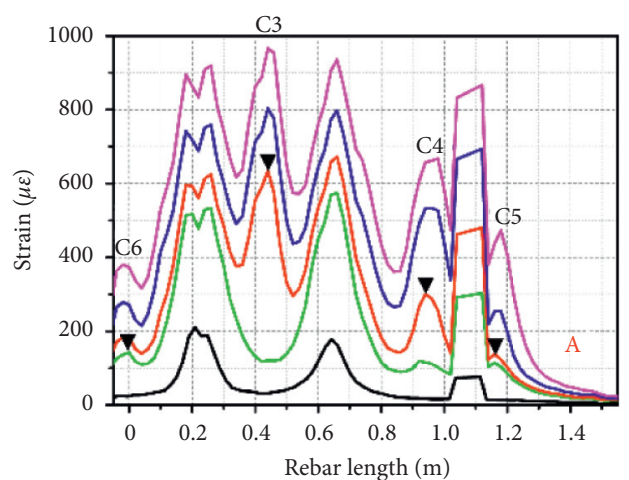

(b)

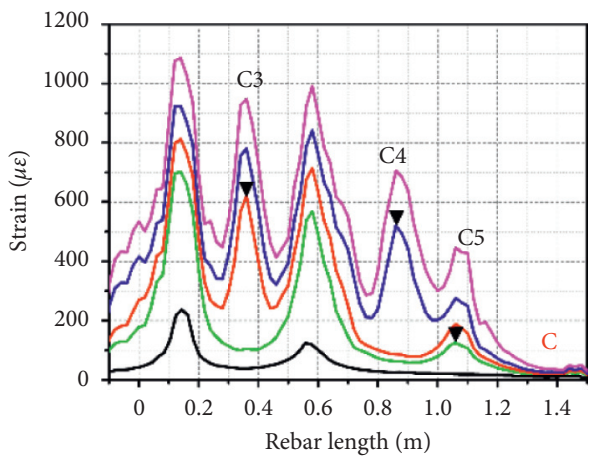

(d)

$$
\begin{aligned}
& -300 \mathrm{kN}(\Delta / L=0.15 \%) \\
& -500 \mathrm{kN} \\
& -600 \mathrm{kN}(\Delta / L=0.30 \%)
\end{aligned}
$$

$700 \mathrm{kN}(\Delta / L=0.40 \%)$

Figure 8: Damage status at $0.45 \%$ drift (a) and strain profile measured in top fibers $\mathrm{A}, \mathrm{B}$, and $\mathrm{C}$ at drift levels below $0.45 \%((\mathrm{~b}-\mathrm{d})$.

increase in strain at a drift level beyond 1.5\% (i.e., a $2200 \mathrm{kN}$ lateral load). This is in good agreement with a remarkable stiffness degradation of the RC structure and yielding of top longitudinal rebars as shown in Figure 6. However, as the drift level increases, there is an increase in the degree of difficulty of crack detection due to a smoothing tendency of strain measurement. Strain profiles in fibers A, B, and C at $0.9 \%$ drift are provided in Figure 9(c), in which peaks are faintly visible to locate the position of all the cracks from $\mathrm{C} 1$ to C7. When the maximum lateral load of $2628 \mathrm{kN}$ at $4.8 \%$ drift was reached, the value of measured strain in fibers has seemly reached to 15000 microstrain which is the strain measuring limits of optical fiber sensing system, as shown in Figure 9(d). Several previous studies $[7,14,15]$ have reported strain-reading anomalies (SRA) in the form of localized and excessviely large strain peaks for optical fiber sensors bonded to reinforcing bars, which looks very similar to what can be found in Figure 9(d).

\subsection{Strain Profile in Steel Bars and Crack Distribution on the} Lateral Side. The cracks on the lateral side of concrete at $1.1 \%$ drift are mapped in Figure 10(a), which represented a remarkable diagonal pattern induced by the combined effect of flexure and shear.
The strain profiles measured on side steel bars D, E, and F were presented in Figures 10(b) 10(d). Compared with 4 local peaks that represent the cracks $\mathrm{C} 2 \sim \mathrm{C} 5$ occurring in strains obtained from steel bar F, only 3 peaks were captured for steel bar E. In addition, the distance change between cracks $\mathrm{C} 2$ and $\mathrm{C} 3$ and cracks $\mathrm{C} 2$ and $\mathrm{C} 4$ in steel bars $\mathrm{E}$ and $\mathrm{F}$ indicates a slight left-shift tendency of crack development. This is in a good agreement with visual inspection. It is worth noting that the steel bar $\mathrm{D}$, which was right at the bottom of strut, presents a compressive strain along the total length. Meanwhile, a $1 / 3$ part of steel bar E away from the supporting side of strut shows a compressive strain as well. The difference of strain status over the depth of section provides a tool of distinguishing compression zone from tension zone.

Figure 11(a) displays the final damage status of the RC structure on the lateral side, where a large quantity of diagonal cracks was observed along the span and depth of tested structure.

As shown in Figure 11(b), at a drift level beyond 1.5\%, racks $\mathrm{C} 1$ and $\mathrm{C} 7$ has extended to a $1 / 2$ depth of the strut which corresponds to the location of steel bar F, while the Cracks C2 $\sim 5$ has been inspected at this location in an earlier loading step. At the other end of steel bar F, two new spikes emerge in 

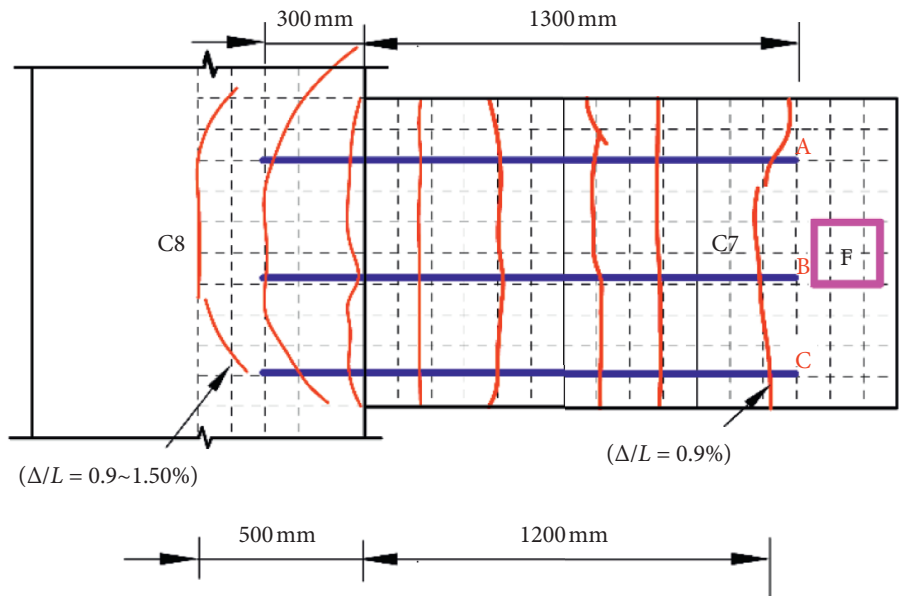

(a)

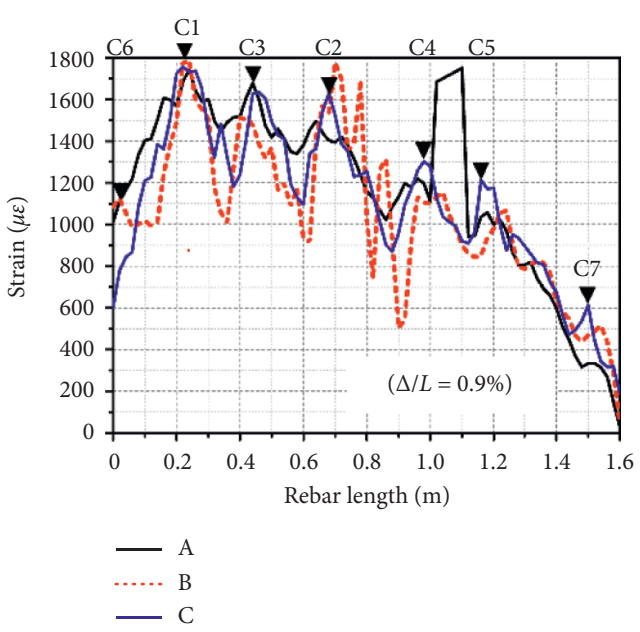

(c)

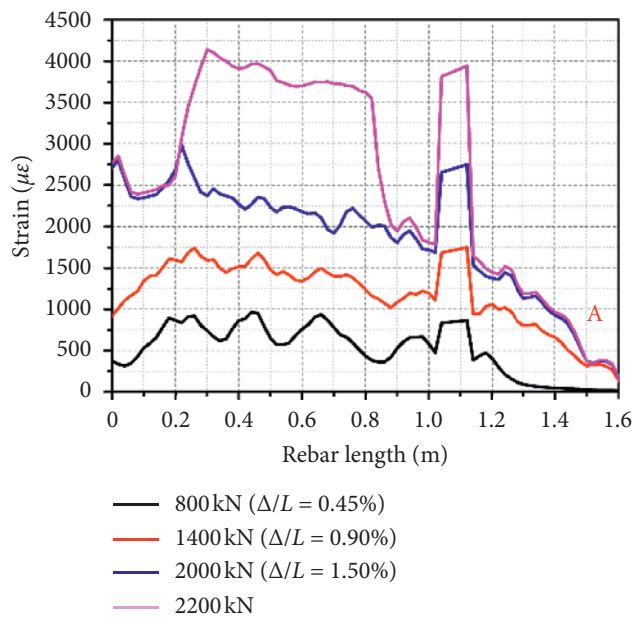

(b)

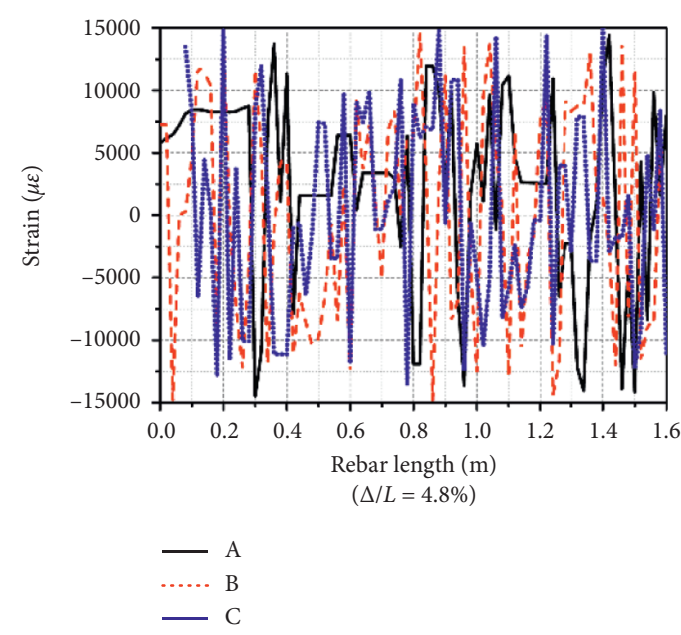

(d)

Figure 9: Damage status at 1.5\% drift (a), strain profile measured in top fiber A at drift levels below 1.5\% (b), and strain profile measured in top fibers $\mathrm{A}, \mathrm{B}$, and $\mathrm{C}$ at $0.9 \%$ and $4.8 \%$ drift levels (c, d).

the strain profile, which probably resulted from the development of crack C6 and a new crack initiation between $\mathrm{C} 1$ and C6, although this cannot be demonstrated by visual inspection. This is because there is not a free surface for the $300 \mathrm{~mm}$ long part of the steel bar to check theh depth the crack C6 and the potential new crack have extended to. After an elaborated investigation of cracks on the top surface of strut (see Figure 6), a new crack between C1 and C6 was finally found, initiating at a drift level a little higher than $0.5 \%$ but not running through the width of cross section even at the end of test. This finding confirms our speculation that the new crack between $\mathrm{C} 1$ and $\mathrm{C} 6$ on the surface of the waler beam has extended nearly to a half depth at a drift level beyond $1.5 \%$.

The strain profiles measured on steel bars D, E, and F at $1.75 \%$ and $4.8 \%$ drift levels are given in Figures 11(c) 11(d). The distribution of compressive strain on steel bar D shows a maximum value attained at an about $0.5 \mathrm{~m}$ distance from the left end of steel bar, which corresponds to a concrete crush observed in the test very well. The tensile strain profile on steel bar $\mathrm{F}$ at $4.8 \%$ drift level refers to strain-reading anomalies (SRA), similar to the strains measured on top fibers at a very high drift level, mentioned in the previous section.

\subsection{Two Issues to Be Discussed}

3.4.1. How to Reduce the Effect of Temperature on the Fiber Strain Measurements. The Rayleigh-based Optical Frequency Domain Reflectometry (OFDR) technique adopted in this paper can consider the optic fiber as continuously distributed Fiber Bragg Gratings (FBG) with weak random periods $[17,18]$. As the temperature changes, the density, refractive index, and free energy of optic fiber will change and further induce the shift of Rayleigh scattering spectrum [19]. Thus, the distributed optic fiber is synchronously sensitive to the surrounding strain and temperature. Currently, there are three approaches to distinguish and offset the influence of temperature on strain measurement. 


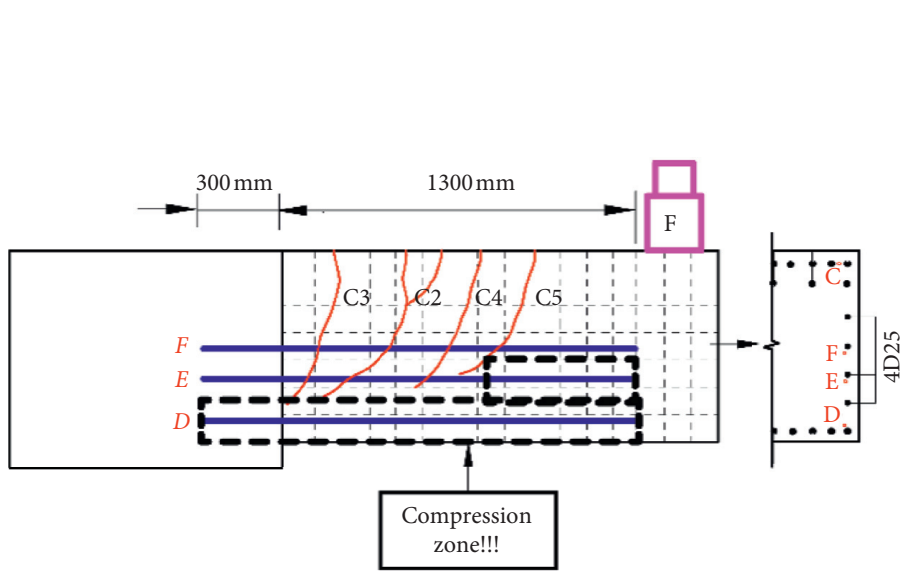

(a)

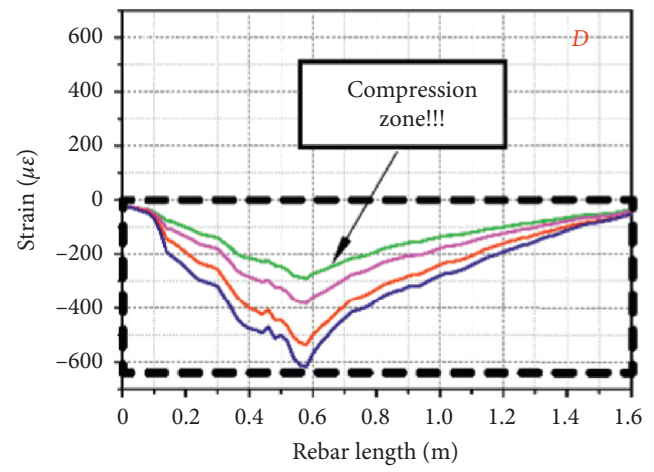

(c)

$$
\begin{aligned}
& -300 \mathrm{kN}(\Delta / L=0.15 \%) \\
& -400 \mathrm{kN} \\
& -600 \mathrm{kN}(\Delta / L=0.30 \%)
\end{aligned}
$$

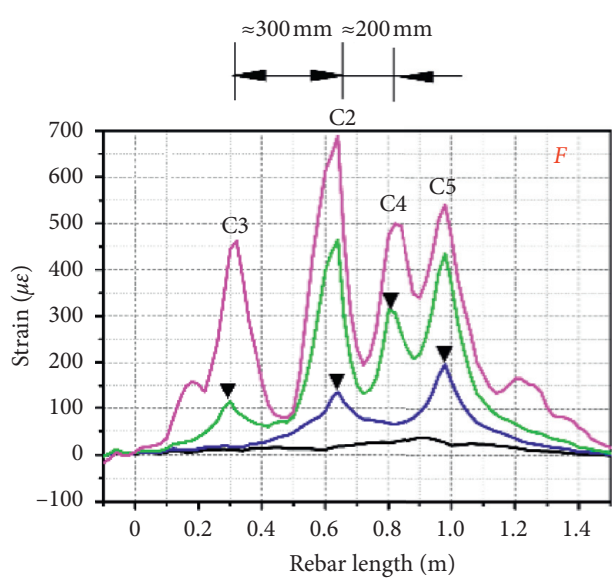

(b)

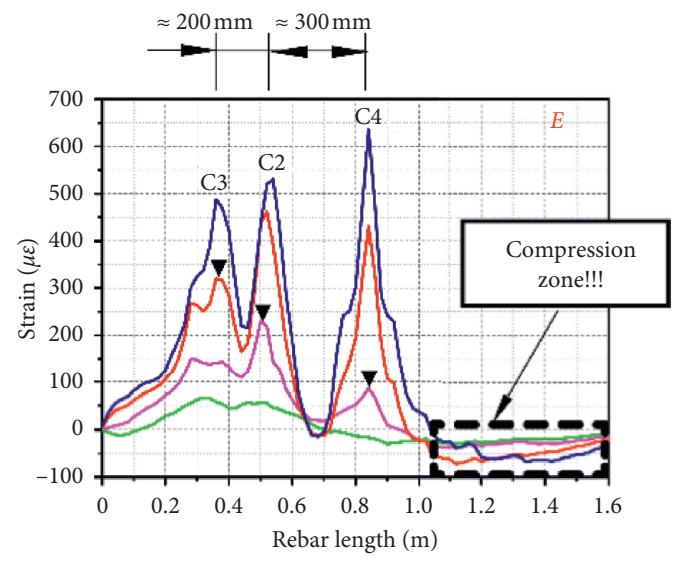

(d)

Figure 10: The damage status on lateral side at $1.1 \%$ drift (a) and strain profiles measured on side steel bars D, E, and F at drift levels below $1.1 \%(b-d)$.

The first is reference optic fiber, which is the simplest and most commonly used method in engineering practice. Inaudi and Glisic [20] developed a specific sensor called SmartProfile, which consists of two bonded and two free single-mode optic fibers embedded in a polyethylene thermoplastic profile. The bonded fibers are attached to the objectives and used for strain monitoring, while the free loose fibers are used for temperature measurements and to compensate temperature effects on the bonded fibers. In recent application cases, the free fibers and bonded fibers are not necessarily combined in one package but can be separately set up in the parallel vicinity. However, the space limitation may cause difficulties in the layout of reference optic fiber.

The second is Landau-Placzek Ratio method. The Landau-Placzek Ratio (LPR) in an optic fiber has a dependence on the thermophysical property of medium. Bansal and Doremus [21] and Wait and Newson [22] showed that LPR keeps an inverse proportionality with the temperature. Hence, the temperature measurement and compensation on strain measurement can be achieved through LPR by analyzing the Rayleigh and Brillouin scattered light.

The third is combined Raman anti-Stokes Light method proposed by Alahbabi et al. [23]. The magnitude of the intensity of the anti-Stokes Raman signal permits the determination of the temperature. Hence, the independent temperature can be easily obtained and then allows the independent strain to be determined. The demodulation system combined Raman and Brillouin scattering analysis is regarded as the potential prospect in the future.

Due to its high sensitivity and short sensing range limit, OFDR technique is most suitable for laboratory-scale model experiment. Besides, according to the existent application cases and experience $[24,25]$, if the loading time is relatively short or the environmental temperature has little variation, then the temperature compensation on strain measurement can be neglected. For the laboratory test stated in this paper, the temperature effect was not considered because the optic fiber sensors were well embedded in the strut component; both the concrete and rebar temperature deviation were 

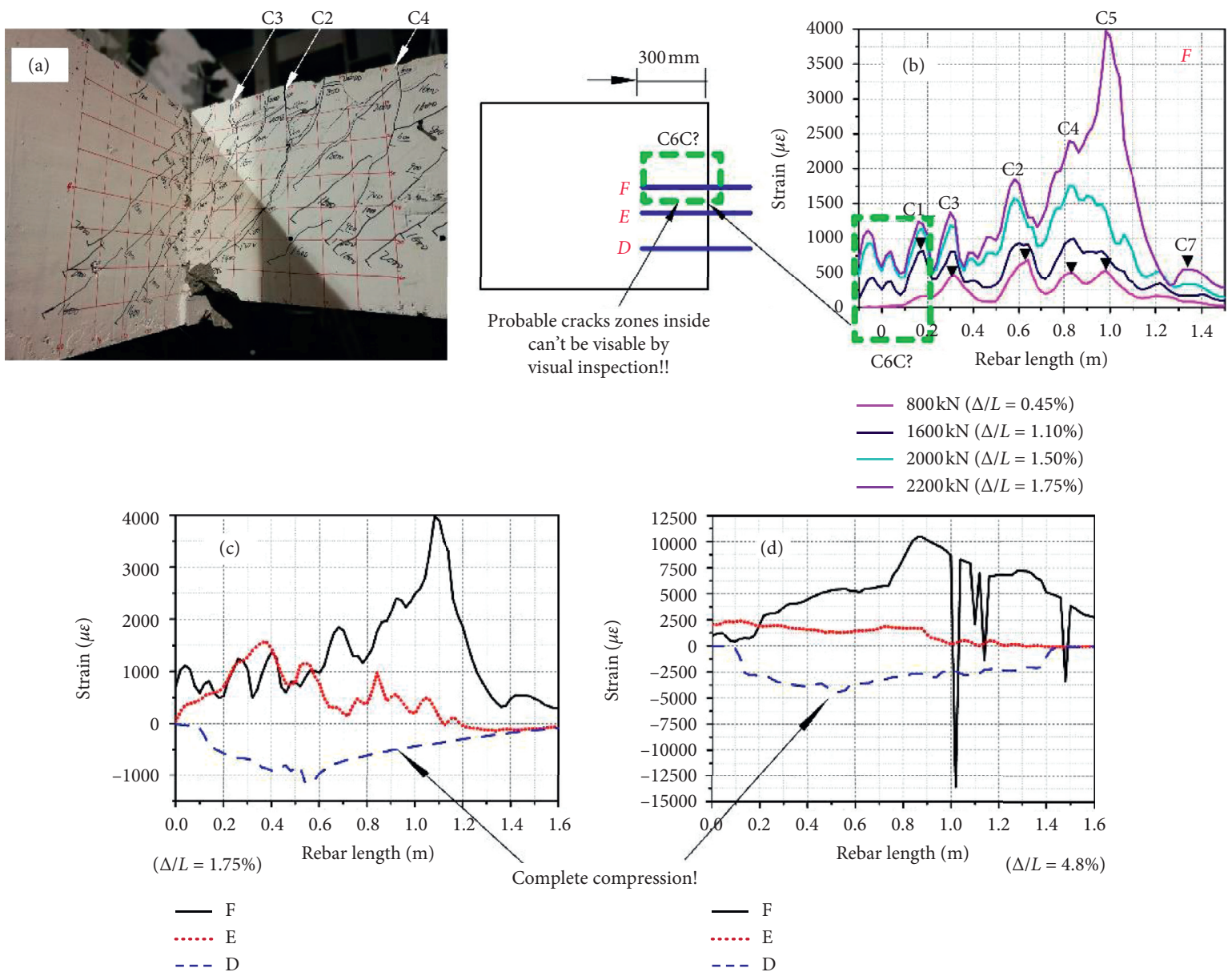

Figure 11: Damage status at 5.4\% drift at side view (a), strain profile measured on side steel bar F at drift levels below $1.75 \%$ (b), and strain profile measured on side steel bars D, E, and F at $1.75 \%$ and $4.8 \%$ drift levels (c, d).

extremely small and the loading duration lasted only 3 hours.

\subsubsection{Minimum Distance between Two Cracks That Can Be} Distinguished. The above analysis shows that the minimum distance of two apparently visible cracks in this experiment was approximately $20 \mathrm{~cm}$, for example, $\mathrm{C} 3$ and $\mathrm{C} 1$ and $\mathrm{C} 4$ and $\mathrm{C} 5$ in Figure 8. All these cracks have been distinguished successfully and easily. However, it is really hard to say how close a distance between two cracks can be distinguished. Actually, in a $30 \mathrm{~cm}$ long fiber length, C6 and a new crack were detected as demonstrated in Figure 11. This implies that two cracks with a distance of $10 \mathrm{~cm}$ or $15 \mathrm{~cm}$ have been also identified with a spatial resolution of $2 \mathrm{~cm}$.

In theory, the higher the spatial resolution was set for the data acquisition system, the smaller crack distance can be identified. Actually, we are recently attempting to detect the crack distribution and evolution in a model test with a scale ratio of $1: 20$. A highest spatial resolution of $1 \mathrm{~mm}$ allowed by interrogator OSI-S by Semicon will be chosen, as the minimum crack distance is expected to be at a level about $10 \mathrm{~mm}$. The observed minimum crack distance in the realsize structure was about $20 \mathrm{~cm}$.

\section{Conclusions}

The study reported in this paper is an attempt to employ optical fiber sensors embedded in a reinforced concrete structure to detect the initiation, location, and propagation of cracks, especially in the case of a free concrete surface unavailable for visual inspection. This goal is achieved by installing a thin optical fiber at multiple locations to form a smart sensitive network within the concrete structure, which provides a possibility to track the path of crack growth. A Rayleigh backscattering technique-based interrogator (OSI$S$ by Semicon) with a very high space resolution and measurement accuracy is a vital device in this distributed optical fiber sensing system, although it is quite costly. Based on this study, the following conclusions can be drawn:

(1) The strain profile measured from optical fibers bonded to small diameter steel bars embedded in concrete structure, which were installed in the vicinity of the longitudinal reinforcing bars, shows a similar shape to optical fibers directly glued to concrete surface reported in previous studies. The initiation of cracking and its location can be identified by the local spikes in the tensile strain profile. 
(2) It is much easier to implement the recognition of crack at a low loading or deformation condition because of an increased difficulty to find out the spikes in a smooth tensile strain profile acquired at higher loading level. Besides, strain-reading anomalies might be encountered as the measured strain increases under this condition.

(3) The reasonable arrangement of optical fibers embedded in concrete structure allows capturing the path of crack growth and then realizing the recognition of crack orientation and depth. The distinguishing of compression and tension zone along the height of cross section for concrete structure under flexure and shear was also achieved.

Future work in relation to a further strain data analysis needs to be conducted in order to investigate the quantitative relationship between the strain values and cracking degree and to reveal the inherent mechanism of monitoring scheme proposed in this study.

\section{Data Availability}

The data used in the study are available upon request.

\section{Conflicts of Interest}

The authors declare no conflicts of interest.

\section{Acknowledgments}

This work was funded by the National Natural Science Foundation of China (51678248, 51808230, and 51878296), the Independent Research Program of State Key Laboratory of Subtropical Building Science (2017KB15), South China University of Technology, the Open Research Fund of State Key Laboratory of Simulation and Regulation of Water Cycle in River Basin (IWHR-SKL-KF201818), and China Institute of Water Resources and Hydropower Research. Thanks are due to Dr. Fei Wang from Tongji University and Dr. Guangqing Wei from Suzhou NanZee Sensing Technology Co., Ltd., for providing the valuable suggestions on the monitoring scheme.

\section{References}

[1] A. Mohan and S. Poobal, "Crack detection using image processing: a critical review and analysis," Alexandria Engineering Journal, vol. 57, no. 2, pp. 787-798, 2018.

[2] G. Rodríguez, J. R. Casas, and S. Villaba, "Cracking assessment in concrete structures by distributed optical fiber," Smart Materials and Structures, vol. 24, no. 3, Article ID 035005, 2015.

[3] J.-M. Henault, M. Quiertant, S. Delepine-Lesoille et al., "Quantitative strain measurement and crack detection in RC structures using a truly distributed fiber optic sensing system," Construction and Building Materials, vol. 37, pp. 916-923, 2012.

[4] S. Villalba and J. R. Casas, "Application of optical fiber distributed sensing to health monitoring of concrete structures,"
Mechanical Systems and Signal Processing, vol. 39, no. 1-2, pp. 441-451, 2013.

[5] A. Barrias, J. R. Casas, S. Villalba, and G. Rodriguez, "Health monitoring of real structures by distributed optical fiber," Life-Cycle of Engineering Systems, vol. 16, pp. 748-755, 2016.

[6] S. Haefliger, J. Mata-Falcón, and W. Kaufmann, "Application of distributed optical measurements to structural concrete experiments," in Proceedings of the Fourth Conference on Smart Monitoring, Assessment and Rehabilitation of Civil Structures (SMAR 2017), Zurich, Switzerland, September 2017.

[7] A. Barrias, J. R. Casas, and S. Villalba, "Application study of embedded rayleigh based distributed optical fiber sensors in concrete beams," Procedia Engineering, vol. 199, pp. 20142019, 2017.

[8] A. Brault, N. A. Hoult, T. Greenough, and I. Trudeau, "Monitoring of beams in an RC building during a load test using distributed sensors," Journal of Performance of Constructed Facilities, vol. 33, no. 1, Article ID 04018096, 2019.

[9] M. Bado, J. Casas, and A. Barrias, "Performance of Rayleighbased distributed optical fiber sensors bonded to reinforcing bars in bending," Sensors, vol. 18, no. 9, p. 3125, 2018.

[10] A. Barrias, G. Rodriguez, J. R. Casas, and S. Villalba, “Application of distributed optical fiber sensors for the health monitoring of two real structures in Barcelona," Structure and Infrastructure Engineering, vol. 14, no. 7, pp. 967-985, 2018.

[11] A. Brault and A. N. Hoult, "Monitoring reinforced concrete serviceability performance using fiber-optic sensors," $A C I$ Structural Journal, vol. 116, no. 1, pp. 57-70, 2019.

[12] A. Malek, A. Scott, S. Pampanin, and N. A. Hout, "Postyield bond deterioration and damage assessment of RC beams using distributed fiber-optic strain sensing system," Journal of Structural Engineering, vol. 145, no. 4, Article ID 04019007, 2019.

[13] A. Barrias, J. Casas, and S. Villalba, "Embedded distributed optical fiber sensors in reinforced concrete structures-a case study," Sensors, vol. 18, no. 4, p. 980, 2018.

[14] M. Davis, N. A. Hoult, and A. Scott, "Distributed strain sensing to determine the impact of corrosion on bond performance in reinforced concrete," Construction and Building Materials, vol. 114, pp. 481-491, 2016.

[15] M. Davis, N. A. Hoult, and A. Scott, "Distributed strain sensing to assess corroded RC beams," Engineering Structures, vol. 140, pp. 473-482, 2017.

[16] Ministry of Housing and Urban-Rural Development of the People's Republic of China (MOHURD), Code for Design of Concrete Structures GB50010, China Architecture \& Building Press, Beijing, China, 2010.

[17] B. Shi, D. Zhang, and H. H. Zhu, Distributed Fiber Optic Sensing for Geoengineering Monitoring, Science Press, Beijing, China, 2019.

[18] K. Yüksel, M. Wuilpart, V. Moeyaert, and P. Mégret, "Novel monitoring technique for passive optical networks based on optical frequency domain reflectometry and fiber Bragg gratings," Journal of Optical Communications and Networking, vol. 2, no. 7, pp. 463-468, 2010.

[19] M. Froggatt and J. Moore, "High-spatial-resolution distributed strain measurement in optical fiber with Rayleigh scatter," Applied Optics, vol. 37, no. 10, pp. 1735-1740, 1998.

[20] D. Inaudi and B. Glisic, "Development of distributed strain and temperature sensing cables," in Proceeding of the 17th International Conference on Optical Fibre Sensors, Bruges, Belgium, May 2005. 
[21] N. P. Bansal and R. H. Doremus, Handbook of Glass Properties, Academic Press, Cambridge, MA, USA, 1986.

[22] P. C. Wait and T. P. Newson, "Landau Placzek ratio applied to distributed fibre sensing," Optics Communications, vol. 122, no. 4-6, pp. 141-146, 1996.

[23] M. N. Alahbabi, Y. T. Cho, and T. P. Newson, "Simultaneous temperature and strain measurement with combined spontaneous Raman and Brillouin scattering," Optics Letters, vol. 30, no. 11, pp. 1276-1278, 2005.

[24] A. Klar, P. J. Bennett, K. Soga et al., "Distributed strain measurement for pile foundations," Proceedings of the Institution of Civil Engineers-Geotechnical Engineering, vol. 159, no. 3, pp. 135-144, 2006.

[25] Y. Lu, B. Shi, G. Q. Wei, S. E. Chen, and D. Zhang, "Application of a distributed optical fiber sensing technique in monitoring the stress of precast piles," Smart Materials and Structures, vol. 21, no. 11, Article ID 115011, 2012. 